\title{
The role of depression and social support in non-fatal drug overdose among a cohort of injection drug users in a Canadian setting
}

\author{
Roman Pabayo ${ }^{1}$, Carmela Alcantara ${ }^{2}$, Ichiro Kawachi ${ }^{1}$, Evan Wood ${ }^{3,4,5}$, and Thomas \\ $\mathrm{Kerr}^{3,4,5}$ \\ ${ }^{1}$ Department of Society, Human Development, and Health, Harvard School of Public Health, 677 \\ Huntington Avenue, Boston, MA, USA, 02115 \\ ${ }^{2}$ Department of Medicine, Columbia University Medical Center, 622 West $168^{\text {th }}$ Street, $\mathrm{PH}-9$, \\ Room 9-319, New York, NY, USA, 10032 \\ ${ }^{3}$ British Columbia Centre for Excellence in HIV/AIDS, St. Paul's Hospital, 608-1081 Burrard \\ Street, Vancouver, BC, CANADA, V6Z 1 Y6
}

${ }^{4}$ School of Population and Public Health, University of British Columbia, 5804 Fairview Avenue, Vancouver, BC, CANADA, V6T 1 Z3

${ }^{5}$ Department of Medicine, University of British Columbia, St. Paul's Hospital, 608-1081 Burrard Street, Vancouver, BC, CANADA, V6Z 1 Y6

\begin{abstract}
Objectives-Non-fatal overdose remains a significant source of morbidity among people who inject drugs (IDU). Although depression and social support are important in shaping the health of IDU, little is known about the relationship between these factors and overdose. Therefore, we sought to determine whether depressive symptoms and social support predicted non-fatal overdose among IDU in a Canadian setting.
\end{abstract}

\begin{abstract}
Methods-Data were derived from three prospective cohorts of people who use drugs: the Vancouver Injection Drug Users Study (VIDUS), the ACCESS Cohort, and the At-Risk Youth Study (ARYS). Multilevel modeling was used to determine if depression and social support were significant predictors of non-fatal overdose across time. Analyses were stratified by sex.
\end{abstract}

Results-There were 1,931 participants included in this analysis, including 653 (33.8\%) females and $69(3.6 \%)$ youth 20 years old or younger. Depressed men (Adjusted odds ratio [AOR] $=1.53$,

(C) 2013 Elsevier Ireland Ltd. All rights reserved.

Send correspondence to: Roman Pabayo, Department of Social and Behavioral Sciences, Harvard School of Public Health, 677 Huntington Avenue, Boston, MA, USA, 02115, Tel: (617) 384-8814, Fax: (617) 432-3123, rpabayo@ hsph.harvard.edu.

Conflict of Interest

No conflict declared

Contributors

RP had access to the data in the study and takes responsibility for the integrity of the data and the accuracy of the results. RP also wrote the first draft of the manuscript and undertook the analysis. Authors EW and TK designed the study and wrote the study protocol. Author CA helped manage the literature searches. Authors CA and IK provided support on the conceptual framework. All authors critically reviewed the first draft of the manuscript and approved the final version to be submitted.

Publisher's Disclaimer: This is a PDF file of an unedited manuscript that has been accepted for publication. As a service to our customers we are providing this early version of the manuscript. The manuscript will undergo copyediting, typesetting, and review of the resulting proof before it is published in its final citable form. Please note that during the production process errors may be discovered which could affect the content, and all legal disclaimers that apply to the journal pertain. 
$95 \%$ confidence intervals $[\mathrm{CI}]=1.25,1.87$ ) and women (Adjusted odds ratio $[\mathrm{AOR}]=2.23,95 \%$ confidence intervals $[\mathrm{CI}]=1.65,3.00$ ) were more likely to experience a non-fatal overdose. Further, among women, those who reported having 3 or more persons they could rely upon for social support were less likely to experience a non-fatal overdose ( $\mathrm{AOR}=0.54,95 \% 0.31,0.93$ ).

Conclusion-Although depression was a significant predictor of non-fatal drug overdose, social support was a significant predictor among women only. Possible strategies to prevent non-fatal overdose may include identifying IDU experiencing severe depressive symptoms and providing targeted mental health treatments and mobilizing interpersonal social support among IDU, especially among women.

\section{Keywords}

Depression; social epidemiology; substance use; longitudinal data analysis; social support

\section{INTRODUCTION}

Non-fatal overdose is an inadvertent or deliberate consumption of a dose much larger than that either habitually used by the individual or ordinarily used for treatment of an illness, and often results in a serious toxic reaction. Although considerably more attention has been devoted to the study of fatal overdose, non-fatal overdose is more common and is associated with a range of harms. For instance, non-fatal overdose remains an important determinant of morbidity among injection drug users (IDU), and can lead to aspiration pneumonia, hypoxic brain injury, rhabdomyolysis, and renal failure (Darke and Hall, 2003). Prevalence estimates of IDU who have experienced non-fatal overdoses in the previous 12 months is $17 \%$ among opiate users in Canada (Milloy et al., 2008b). Other estimates include 58.5\% lifetime history of non-fatal overdose and $8.9 \%$ non-fatal overdose in the last six months among IDU in Vancouver (Milloy et al., 2008b). Among rural drug users in Kentucky USA, 28\% report a lifetime non-fatal overdose (Havens et al., 2011).

Previous prospective research with IDU in Vancouver, BC, identified several predictors of non-fatal overdose, such as heroin and cocaine injection, benzodiazepine use, requiring help injecting, binge drug use, homelessness, alcohol use, street injecting, non-injectable opiate use, speedball use, and recent incarceration (Kerr et al., 2007a). Other observed risk factors for non-fatal overdose include sex trade involvement (Milloy et al., 2008a). An Australian study identified extensive polydrug use and having overdosed in the previous year as significant predictors of non-fatal overdose (Darke et al., 2005). A study in the US found experiencing serious withdrawal symptoms in the past two months and younger age as significant determinants of non-fatal overdose (Coffin et al., 2007). However, more research is required to identify specific subgroups of drug users who are at greater risk for non-fatal overdose. For example, among rural drug users, significant risk factors associated with a greater number of non-fatal overdoses included history of drug treatment, 30-day history of injection of prescription opioids, meeting diagnostic criteria for post-traumatic stress disorder (PTSD) and having more members in one's support network (Havens et al., 2011). Yet, the role of mental health status as a risk factor for overdose has not been thoroughly examined (Tobin and Latkin, 2003).

Several studies have investigated the relationship between depression and drug use, with the prevalence of depression among IDU ranging from 25\% to $81 \%$ (Callaly et al., 2001, Springer, 2012, Teesson et al., 2005, Pilowsky et al., 2011, Conner et al., 2008, MackesyAmiti et al., 2012). A meta-analysis of 55 studies investigating the association between depression and substance related behaviors among IDU identified 55\% of participants with above average levels of depressive symptoms (Conner et al., 2008).

Drug Alcohol Depend. Author manuscript; available in PMC 2014 October 01. 
Prior research contends that individuals with psychiatric disorders, such as mood and anxiety disorders, engage in drug use to self-medicate or cope with their psychiatric disorders (Khantzian, 1985, Potvin et al., 2003). Thus depressed IDU might be more likely to use illicit drugs to self-medicate or ease their depressive symptoms and improve their mood (Weiss et al., 1992, Bolton et al., 2009). It has been observed that among IDU, those who reported depressive symptoms are significantly more likely to have overdosed after adjusting for age, gender, injection frequency, and physical impairment (Tobin and Latkin, 2003). However, the temporal relationships between depressive symptoms and drug overdose have not been elucidated (Tobin and Latkin, 2003).

Researchers hypothesize that drug use leading to overdose may either be an accidental act or a suicide attempt (Darke et al., 2004, Rossow and Lauritzen, 1999, Neale, 2000, Vingoe et al., 1999). Some researchers argue that those who abuse drugs may suffer from poor selfesteem and hopelessness that leads to a careless attitude towards one's own life, leading to an accidental non-fatal overdose (Rossow and Lauritzen, 1999, Neale, 2000). Another study identified consumption of an unfamiliar substance, unexpectedly using a pure form of the drug, such as heroin, and consuming drugs in an uncontrolled manner while under the influence of alcohol as predictors of accidental non-fatal overdose (Pfab et al., 2006). A recent longitudinal study identified thoughts of suicide acted as an independent predictor of accidental overdose (Richer et al., 2012).

Furthermore, social network composition has been found to be associated with non-fatal overdose (Latkin et al., 2004, Havens et al., 2011). For example, having a greater number of network members who were IDU and a larger number of conflictual social ties among the network members were associated with increased risk of overdose (Latkin et al., 2004). Although social support is often viewed as a beneficial influence on the maintenance of health promoting behaviors, in the context of networks involving other IDU, it is possible that access to more friends who inject drugs may have the opposite effect, i.e., the so-called dark side of social support (Turner, 1994). In other words, social connectedness can in some instances serve to transmit social pressure to conform to unhealthy norms within a social group, whether the behavior is sharing needles, or experimenting with new drugs (Cohen, 2004, Umberson et al., 2010). On the other hand, research also suggests that the amount of available social supports generates positive psychological states that in turn buffer the deleterious influence of stress, and strengthens the ability of the recipient to cope with adversity (Cohen, 2004, Cohen and Lemay, 2007). According to this view, among IDUs, social support may ameliorate the effect of depression on the risk for non-fatal overdose.

Previous research has indicated that women might be more responsive to social support than men (Flaherty and Richman, 1989; Wilson et al., 1999; Shumaker and Hill, 1991). Men have been socialized differently such that they receive more task-focused support during childhood (Belle, 1989), and therefore are more likely to seek out instrumental rather than emotional support (Kliewer et al., 1990; Carver et al., 1989; Lepore et al., 1993). For example, instead of seeking social support from social relationships, males might be more likely to resort to stress reducing activities to cope.

Although previous cross-sectional studies have identified correlates of non-fatal drug overdose, investigations involving cohorts that examine the relationship between depression, social support and non-fatal overdose are needed. Accordingly, the objectives of this study were to determine whether depression and the level of social support were independent determinants of non-fatal overdose among IDU participating in three cohort studies in Vancouver, Canada. We also sought to test if those who were depressed and receiving more social support were less likely to experience non-fatal overdose in comparison to those who had little or no social support. 


\section{METHODS}

The At Risk Youth Study (ARYS), Vancouver Injection Drug Users Study (VIDUS) and AIDS Care Cohort to Evaluate Access to Survival Services (ACCESS) are open prospective cohorts of drug users in Vancouver, Canada. These studies comprise a larger initiative focused on the study of the natural history of injection drug use. Recruitment procedures for the three studies are similar, with the primary modes of enrollment being self-referral, word of mouth, and street outreach. Participants of all studies must have resided in the greater Vancouver region and provided informed consent to be eligible. Each study also had specific eligibility criteria, which have been described previously (Wood et al., 2006b). Briefly, ARYS consists of drug-using street-involved youth; thus, eligibility criteria included being between the age of 14 and 26 and the use of illicit drugs other than or in addition to marijuana in the past 30 days. VIDUS is a study of HIV negative IDU in which all participants must have injected an illicit drug in the previous month to be eligible for inclusion. ACCESS is a cohort of HIV positive individuals, who, similar to those in ARYS, must have recently used an illicit drug other than or in addition to marijuana. Detailed sampling and recruitment procedures for these three cohorts have also been described elsewhere (Tyndall et al., 2003, Strathdee et al., 1998, Wood et al., 2006a, 2004, 2008). Only participants who were active injectors in the past six months at baseline were included in this investigation.

At baseline and semi-annually, participants completed a lengthy interviewer-administered questionnaire. Sociodemographic data, as well as information pertaining to drug use patterns, risk behaviors, and health care utilization were collected. The survey for each study consists of a uniform set of questions, which permits the aggregation and analysis of data from all enrolled participants. Nurses collected blood samples for HIV and hepatitis C serology, as well as HIV disease progression, and also provided basic medical care and referrals to appropriate health care services. All individuals who completed a baseline survey between September 2005 and May 2008 were eligible for inclusion. Participants received $\$ 20$ for each study visit. The University of British Columbia/Providence Health Care Research Ethics Board approved all studies.

\subsection{Measures}

At baseline, participants were asked to identify their biological sex at birth and their current sexual orientation. "Sexual minority status" was defined as answering affirmatively to one of the following: gay, lesbian, bisexual, transsexual, transgendered, or other. Participants who refused to report their sex at birth or sexual orientation were excluded from this analysis.

The primary outcome was non-fatal overdose. Since polysubstance injection drug use is the norm in our setting, and because we were interested in overdoses involving various substances, we used a broad definition of non-fatal overdose. We simply asked participants, "In the last six months, have you overdosed by accident (i.e., where you had a negative reaction from using too much drugs)?" Participants who responded "yes" were defined as experiencing a non-fatal overdose in all subsequent analyses. This definition was pilot tested during questionnaire development.

Predictor variables of interest in this analysis were chosen based on previous work (Kerr et al., 2007a). Sociodemographic information included sex, age, education, sexual orientation, and cohort (ARYS, VIDUS, and ACCESS). Time-varying variables and exposures that were measured at baseline and updated repeatedly during follow-up included drug use (heroin, cocaine, speed, crystal meth, and morphine injection) within the last 6 months, alcohol 
binge, undergoing methadone treatment, needing help injecting, homelessness, relationship status, income assistance support, incarceration in the last 6 months, and HIV status.

At each measurement, we used the Center for Epidemiologic Studies Depression Scale (CES-D) with a standard cut-off of $\geq 16$ to measure the level of depressive symptomatology among participants (Radloff, 1977). Scores above 16 were indicative of severe depressive symptoms and a probable diagnosis of depression (Radloff, 1977). To assess social support, we asked participants "Who do you currently count on for support/friendship?" Response options included partners, ex-partners, spouse, lovers, family members/relatives, friends/ neighbors, coworkers/classmates, health care workers, counselors/therapists, medical doctor/ health care worker, ministers, priests or rabbis, other, and no one. The number of support sources was categorized into none, $1-2$, and 3 or more.

\subsection{Data analysis}

Because non-fatal overdose was nested within individuals, i.e., measured twice a year yearly for the same individuals, we used multilevel modeling analyses, also known as a random intercepts modeling, to examine the relationship between socio-demographic, behavioral, depression, and social support measures and likelihood of non-fatal overdose across time. Time-varying variables (exposures collected at each time point) were tested, as between subject effects on the likelihood of non-fatal overdose. Multilevel models are a generalization of the linear model used in traditional regression analyses. Several authors have shown that ignoring the hierarchical structure of a data set can lead to inferential errors and that estimating random effect coefficients can more adequately model data structures typically obtained in field research (Diez-Roux, 2000, Raudenbush and Bryk, 2002). Cleaning and recoding the data were performed with Stata (Version 12.0) and Multilevel Modeling was performed using HLM 6.04.

To investigate the potential effect of socio-demographic, behavioral, depressive symptoms, and social support on likelihood of non-fatal overdose, we adopted a step-up approach and conducted different sets of analyses (Raudenbush and Bryk, 2002). The initial sample $(n=2,865)$ was restricted to participants who were active IDU $(n=2,012)$ with complete socio-demographic data, resulting in a sample size of $n=1,931(1,931 / 2012=96.0 \%)$. A first set of analyses included only parameters operationalizing time, to explore whether or not the proportion of participants who experienced a non-fatal overdose changed across time (model 1). Then the main exposure, severe depressive symptoms (yes vs. no), was added to the model (model 2). Socio-demographic variables were then added to identify significant predictors associated with non-fatal overdose at each year (model 3). The covariates added included sex, sexual orientation, birthplace (Canada vs. foreign-born, age ( 20 years vs. $>20$ years), and finished high school (yes vs. no). Time-varying covariates included, homelessness (yes vs. no), size of social network (none, 1-2, or 3 or more), relationship status (single vs. in a relationship), welfare (no or recipient), incarcerated in the last 6 months (yes vs. no), HIV status (negative vs. positive), had an alcoholic binge in the last 6 months (yes vs. no), and injected heroin, cocaine, speed, crystal meth, or morphine), all of which were included as moderating variables at baseline. Next, an interaction term of depression X social support was added to the previous models. Since the interaction term was not significant, these results are not presented.

\section{RESULTS}

In total, 1,931 participants with complete socio-demographic data were used for this analysis. Of the sample, $66.2 \%(1,278)$ were male, $63.8 \%(\mathrm{n}=1,231)$ were born in Canada, $85.5 \%(\mathrm{n}=1,650)$ were heterosexual, and $3.6 \%(\mathrm{n}=69)$ were 20 years old or younger (table 1). The proportion of the sample that injected heroin, cocaine, crystal meth, morphine, and 
speed were $54.5 \%, 41.9 \%, 20.7 \%, 19.0 \%$, and $15.4 \%$, respectively. Also, the proportion of the sample that injected both heroin and cocaine was $25.6 \%$. Only a small percentage, $2.1 \%$, injected all of the five drug substances. Of the sample, $3.0 \%$ to $7.6 \%$ reported at least one non-fatal overdose during each 6-month study follow-up.

Multilevel modeling of data pertaining to the likelihood of non-fatal overdose showed that there was significant between person variance. That is the estimate of participants determined from the null models showed that the percentage of males and females who experienced a non-fatal overdose was $5.8 \%$ and $5.7 \%$, respectively. The $95 \%$ plausible value ranges showed that the percentage of participants experiencing a non-fatal overdose during follow-up varied between $3.6 \%$ to $9.1 \%$ among men and 3.6\% to $8.8 \%$ among women. Addition of the dummy variables for time (models 1 ) showed a significant decline in the likelihood of non-fatal overdose especially among women. Among men (table 2), in comparison to baseline, the likelihood of experiencing a non-fatal overdose declined at year $2(\mathrm{OR}=0.84,95 \% \mathrm{CI}=0.65,1.07)$, year $3(\mathrm{OR}=0.79,95 \% \mathrm{CI}=0.61,1.02)$, and year 4 $(\mathrm{OR}=0.67,95 \% \mathrm{CI}=0.49,0.94)$ (significant linear trend, $\mathrm{p}=0.02)$. The decline was much steeper among women (significant linear trend, $\mathrm{p}=0.01$ ). In comparison to baseline, there was a significant decreased likelihood of non-fatal overdose at year $1(\mathrm{OR}=0.64,95 \%$ $\mathrm{CI}=0.45,0.93)$, year $2(\mathrm{OR}=0.58,95 \% \mathrm{CI}=0.42,0.80)$, year $3(\mathrm{OR}=0.45,95 \% \mathrm{CI}=0.42,0.80)$, and year $4(\mathrm{OR}=0.32,95 \% \mathrm{CI}=0.20,0.50)$ (table 3$)$.

Predictors were then tested as moderators of the intercept in the model in order to determine if there were significant differences in likelihood of non-fatal overdose at baseline between groups (e.g., between those born in Canada and those born outside of Canada) (model 3). Among men (table 2), in comparison to those in the ARYS cohort, participants in the VIDUS cohort were significantly less likely to experience non-fatal overdose $(\mathrm{OR}=0.60$, $95 \% \mathrm{CI}=0.42,0.87)$. Being homeless $(\mathrm{OR}=1.26,95 \% \mathrm{CI}=1.01,1.58)$ and being on welfare $(\mathrm{OR}=1.44,1.06,1.95)$ were associated with an increased likelihood of non-fatal overdose. Education, sexual orientation, and birthplace were not significantly associated with non-fatal overdose neither at baseline nor throughout follow-up. Of the drug injection behaviors, cocaine $(\mathrm{OR}=2.54,95 \% \mathrm{CI}=1.93,3.33)$ and speed injection $(\mathrm{OR}=1.50,95 \% \mathrm{CI}=1.18,1.90)$ were significantly associated with increased likelihood of non-fatal overdose in comparison to those who did not inject cocaine or speed (table 2). Similarly, those who binged on alcohol in the past 6 months $(\mathrm{OR}=1.69,95 \% \mathrm{CI}=1.33,2.17)$, in comparison to those who did not, were significantly more likely to experience non-fatal overdose during follow-up. Undergoing methadone treatment $(\mathrm{OR}=0.62,95 \% \mathrm{CI}=0.48,0.80)$ was significantly associated with a decreased likelihood of non-fatal overdose (table 2).

Among women, those who were 20 years old or less $(\mathrm{OR}=2.68,95 \%=1.14,6.92)$ homosexual ( $\mathrm{OR}=1.59,95 \% \mathrm{CI}=1.12,2.25)$, completed high school $(\mathrm{OR}=1.49,95 \%$ $\mathrm{CI}=1.07,2.07)$, and on welfare $(\mathrm{OR}=1.71,95 \% \mathrm{CI}=1.20,2.44)$ were significantly more likely to experience non-fatal overdose during follow-up. Those who binged on alcohol $(\mathrm{OR}=1.59$, $95 \% \mathrm{CI}=1.11,2.30)$, injected cocaine $(\mathrm{OR}=1.84,95 \% \mathrm{CI}=1.29,2.62)$ or morphine $(\mathrm{OR}=1.81$, $95 \% \mathrm{CI}=1.24,2.64)$ were more likely to experience a non-fatal overdose during follow-up.

Our objectives included determining whether depression was a predictor of increased likelihood in non-fatal overdose and if social support was protective. The proportion of participants who experienced a non-fatal overdose was higher among those with depressive symptoms, in comparison to those without symptoms. For example, the estimated proportion of men without and with depressive symptoms who experienced a non-fatal overdose was $4.3 \%$ and $7.7 \%$, respectively. Similarly, among women, the estimated proportion without and with depressive symptoms that experienced a non-fatal overdose were $4.2 \%$, and $10.4 \%$, respectively. Among women only, in comparison to those with no social support, 
participants who had 3 or more sources of social support ( $\mathrm{OR}=0.54,95 \% \mathrm{CI}=0.31,0.93$ ) were significantly less likely to experience a non-fatal overdose at baseline and through follow-up. However, having 1-2 sources of social support was not significantly associated with non-fatal overdose. A depression X social support interaction term was tested and found not to be significantly associated with non-fatal overdose at baseline or during followup among men and women. These findings indicate that although depression is a predictor for non-fatal overdose among men and women, social support is an independent predictor among women as well. Also, a dose response of the effectiveness of social support might be evident because more social support appeared to be indicative of greater protection from non-fatal overdose.

\section{DISCUSSION}

In the current study, non-fatal overdose was common, with $3.0 \%$ to $7.6 \%$ reporting at least one non-fatal overdose during each 6-month study follow-up. We found that among a cohort of IDU in Vancouver, depression was a significant risk factor for non-fatal overdose. In contrast, quantity of social support was protective against non-fatal overdose among women only. These results demonstrate that participants who experience severe depressive symptoms relative to their non-depressed counterparts are at greater risk of further health consequences from their drug use. We found no statistical evidence of an interaction between depression and social support, which indicates that social support is protective among women who experienced depression and those who do not. However, the nonsignificant finding may be due to lack of statistical power.

The findings that mental health status is an independent predictor of non-fatal overdose are consistent with other work (Tobin and Latkin, 2003, Coffin et al., 2007). However, this investigation is one of the first to use longitudinal analysis and thus demonstrates a relationship between depression and non-fatal overdose over time. Individuals with poor mental health status are more likely to use illicit drugs and therefore at greater risk for overdose. Proposed interventions may include identifying people who are at risk of developing depression or are clinically depressed and developing low-threshold (i.e., low barrier or easy to access) and targeted interventions to help them better manage their depressive symptoms.

One possible explanation for depression as a risk factor for non-fatal overdose is the individual unintentionally overdoses. For example, individuals who are depressed are less able to engage in self-maintenance behaviors (e.g., use adaptive emotion-regulation strategies) that would facilitate their taking the precautions needed to avoid over-dosing themselves (Aldao et al., 2010). Moreover, depression may reduce the ability to focus attention whilst they are doing hazardous tasks (Aldao et al., 2010). More investigation is needed to understand the direction of the association between depression and non-fatal overdose across time.

We found a significant association between the number of sources of social support/ friendship and non-fatal overdose, among women only. These results might be due to socialization differences stemming from expected social and occupational roles throughout the life cycle (Flaherty and Richman, 1989). Researchers argue that women have been socialized to develop a greater sensitivity to the needs of themselves and others, leading to a greater dependence on social support and greater ability to provide social support (Flaherty and Richman, 1989). As a result, social support was beneficial among women only. This has important implications for the development and implementation of interventions designed to prevent female IDU in experiencing overdose. 
Although a greater number of sources of social support was significantly associated with a decreased risk for non-fatal overdose, previous research has indicated that more persons in one's support network is associated with increased risk for non-fatal overdose (Havens et al., 2011, Latkin et al., 2004). This difference may be due to the way social support was assessed. We asked participants to name different types of sources of social support. However, the difference might also be driven by who participants identify as belonging to their social network and the perceived quality of social support. For example, prior research suggests that social connectedness can serve as a source of social pressure to encourage positive or negative health behaviors that are considered normative within a social group (Cohen, 2004, Umberson et al., 2010, Christakis and Fowler, 2008). Furthermore, perceived adequacy or quality of social support is more strongly associated with mental health outcomes than quantity of social support (Antonucci and Akiyama, 1987). Thus, it is possible that in our sample, social support network members were more likely to encourage positive health behaviors such as limited or controlled drug use, or participants were more likely to perceive greater quality of social supports, unlike prior studies. Future research should examine the specific characteristics and perceived adequacy of social support and relationship with drug use.

These results also bolster support for interventions that reduce the adverse outcomes associated with overdose, including supervised injection sites and take-home naloxone distribution (Marshall et al., 2011, Center for Disease Control, 2012). While naloxone programs are designed primarily to reduce the likelihood of a fatal overdose, previous evaluations have suggested that supervised injection facilities may serve to reduce the risks associated with non-fatal overdose (Kerr et al., 2007b). Further, health professionals, such as nurses, can provide counseling on site, and provide resources within the community for help to deal with depression and issues related to addiction.

This study has a number of limitations that should be noted. The ARYS, VIDUS, and ACCESS cohorts are not random samples of the eligible population. As a result, findings may not necessarily be generalizable to other urban areas in which drug use is common. Information on all behaviors were collected by self-report, and therefore may be subject to response biases. Also, it should be cautioned on the interpretation of "within-subject" coefficients for repeated binary outcomes since most individuals never experience the event during follow-up (Carlin et al., 2001). Lastly, our failure to detect an interaction between depression and social support may reflect a problem related to statistical power.

In summary, we have demonstrated that among IDU, those who are depressed are more likely to experience non-fatal overdose over time. Also, among women only, those who have many sources of social support are less likely to experience non-fatal overdose. Interventions may include helping those who are experiencing severe depressive symptoms find adaptive ways to deal with mental health symptoms, including referral to low-threshold community mental health programs. Provision of social support through counseling, health professionals, and support groups might also help IDU prevent overdose.

\section{Acknowledgments}

Role of Funding Source

Funding for this study was provided by the National Institutes of Health (NIH) (VIDUS-R01DA011591; ACCESSR01DA021525; ARYS-R01DA028532) and the Canadian Institutes of Health (CIHR) grants HHP-67262 and RAA-79918; NIH and CIHR had no further role in study design; in the collection, analysis and interpretation of data; in the writing of the report; and in the decision to submit the paper for publication.

The authors thank the study participants for their contribution to the research, as well as current and past researchers and staff. This research was undertaken, in part, thanks to funding from the Canada Research Chairs

Drug Alcohol Depend. Author manuscript; available in PMC 2014 October 01. 
program through a Tier 1 Canada Research Chair in Inner City Medicine, which supports Dr. Evan Wood. Dr. Roman Pabayo is a recipient of a post-doctoral Canadian Institutes of Health Research fellowship award.

\section{References}

Aldao A, Nolen-Hoeksema S, Schweizer S. Emotion-regulation strategies across psychopathology: a meta-analytic review. Clin Psychol Rev. 2010; 30:217-237. [PubMed: 20015584]

Antonucci TC, Akiyama H. An examination of sex differences in social support among older men and women. Sex Roles. 1987; 17:737-749.

Bolton JM, Robinson J, Sareen J. Self-medication of mood disorders with alcohol and drugs in the National Epidemiologic Survey on Alcohol and Related Conditions. J Affect Disord. 2009; 115:367-375. [PubMed: 19004504]

Callaly T, Trauer T, Munro L, Whelan G. Prevalence of psychiatric disorder in a methadone maintenance population. Aust NZ J Psychiatry. 2001; 35:601-605.

Carlin JB, Wolfe R, Brown CH, Gelman A. A case study on the choice, interpretation and checking of multilevel models for longitudinal binary outcomes. Biostatistics. 2001; 2:397-416. [PubMed: 12933632]

Center for Disease Control. Community-based opioid overdose prevention programs providing naloxone - United States, 2010. MMWR. 2012; 61:101-105. [PubMed: 22337174]

Christakis NA, Fowler JH. The collective dynamics of smoking in a large social network. New Eng J Med. 2008; 358:2249-2258. [PubMed: 18499567]

Coffin PO, Tracy M, Bucciarelli A, Ompad D, Vlahov D, Galea S. Identifying injection drug users at risk of nonfatal overdose. Acad Emerg Med. 2007; 14:616-623. [PubMed: 17554010]

Cohen S. Social relationships and health. Am Psychol. 2004; 59:676-84. [PubMed: 15554821]

Cohen S, Lemay EP. Why would social networks be linked to affect and health practices? Health Psychol. 2007; 26:410-417. [PubMed: 17605560]

Conner KR, Pinquart M, Duberstein PR. Meta-analysis of depression and substance use and impairment among intravenous drug users (IDUs). Addiction. 2008; 103:524-534. [PubMed: 18261192]

Darke S, Hall W. Heroin overdose: research and evidence-based intervention. J Urban Health. 2003; 80:189-200. [PubMed: 12791795]

Darke S, Ross J, Lynskey M, Teesson M. Attempted suicide among entrants to three treatment modalities for heroin dependence in the Australian Treatment Outcome Study (ATOS): prevalence and risk factors. Drug Alcohol Depend. 2004; 73:1-10. [PubMed: 14687954]

Darke S, Williamson A, Ross J, Teesson M. Non-fatal heroin overdose, treatment exposure and client characteristics: findings from the Australian treatment outcome study (ATOS). Drug Alcohol Rev. 2005; 24:425-432. [PubMed: 16298837]

Diez-Roux AV. Multilevel analysis in public health research. Annu Rev Public Health. 2000; 21:171192. [PubMed: 10884951]

Havens JR, Oser CB, Knudsen HK, Lofwall M, Stoops WW, Walsh SL, Leukefeld CG, Kral AH. Individual and network factors associated with non-fatal overdose among rural Appalachian drug users. Drug Alcohol Depend. 2011; 115:107-112. [PubMed: 21126831]

Kerr T, Fairbairn N, Tyndall M, Marsh D, Li K, Montaner J, Wood E. Predictors of non-fatal overdose among a cohort of polysubstance-using injection drug users. Drug Alcohol Depend. 2007a; 87:39_ 45. [PubMed: 16959438]

Kerr T, Small W, Moore D, Wood E. A micro-environmental intervention to reduce the harms associated with drug-related overdose: evidence from the evaluation of Vancouver's safer injection facility. Intl J Drug Policy. 2007b; 18:37-45.

Khantzian EJ. The self-medication hypothesis of addictive disorders: focus on heroin and cocaine dependence. Am J Psychiatry. 1985; 142:1259-64. [PubMed: 3904487]

Latkin CA, Hua W, Tobin K. Social network correlates of self-reported non-fatal overdose. Drug Alcohol Depend. 2004; 73:61-67. [PubMed: 14687960]

Mackesy-Amiti ME, Donenberg GR, Ouellet LJ. Prevalence of psychiatric disorders among young injection drug users. Drug Alcohol Depend. 2012; 124:70-78. [PubMed: 22226707]

Drug Alcohol Depend. Author manuscript; available in PMC 2014 October 01. 
Marshall BD, Milloy MJ, Wood E, Montaner JS, Kerr T. Reduction in overdose mortality after the opening of North America's first medically supervised safer injecting facility: a retrospective population - based study. Lancet. 2011; 377:1429-1437. [PubMed: 21497898]

Milloy MJ, Kerr T, Mathias R, Zhang R, Montaner JS, Tyndall M, Wood E. Non-fatal overdose among a cohort of active injection drug users recruited from a supervised injection facility. The Am J Drug Alcohol Abuse. 2008a; 34:499-509.

Milloy MJ, Kerr T, Tyndall M, Montaner J, Wood E. Estimated drug overdose deaths averted by North America's first medically-supervised safer injection facility. PloS One. 2008b; 3:e3351. [PubMed: 18839040]

Neale J. Suicidal intent in non-fatal illicit drug overdose. Addiction. 2000; 95:85-93. [PubMed: 10723833]

Pfab R, Eyer F, Jetzinger E, Zilker T. Cause and motivation in cases of non-fatal drug overdoses in opiate addicts. Clin Toxicol. 2006; 44:255-259.

Pilowsky DJ, Wu LT, Burchett B, Blazer DG, Ling W. Depressive symptoms, substance use, and HIVrelated high-risk behaviors among opioid-dependent individuals: results from the Clinical Trials Network. Subst Use Misuse. 2011; 46:1716-1725. [PubMed: 21973307]

Potvin S, Stip E, Roy JY. Schizophrenia and addiction: An evaluation of the self-medication hypothesis. L'Encephale. 2003; 29:193-203.

Raudenbush, S.; Bryk, A. Hierarchical Linear Models: Applications and Data Analysis Methods. Sage Publications; Thousand Oaks, CA: 2002.

Richer I, Bertrand K, Vandermeerschen J, Roy E. A prospective cohort study of non-fatal accidental overdose among street youth: The link with suicidal ideation. Drug Alcohol Rev. 2012 epub ahead of print.

Rossow I, Lauritzen G. Balancing on the edge of death: suicide attempts and life-threatening overdoses among drug addicts. Addiction. 1999; 94:209-219. [PubMed: 10396789]

Springer SA. High rates of depressive symptomatology among injecting drug users in Saskatoon, Canada. Evid Based Ment Health. 2012; 15:9. [PubMed: 22044870]

Strathdee SA, Palepu A, Cornelisse PG, Yip B, O’Shaughnessy MV, Montaner JS, Schechter MT, Hogg RS. Barriers to use of free antiretroviral therapy in injection drug users. JAMA. 1998; 280:547-549. [PubMed: 9707146]

Teesson M, Havard A, Fairbairn S, Ross J, Lynskey M, Darke S. Depression among entrants to treatment for heroin dependence in the Australian Treatment Outcome Study (ATOS): prevalence, correlates and treatment seeking. Drug Alcohol Depend. 2005; 78:309-315. [PubMed: 15893162]

Tobin KE, Latkin CA. The relationship between depressive symptoms and nonfatal overdose among a sample of drug users in Baltimore, Maryland. J Urban Health. 2003; 80:220-229. [PubMed: 12791798]

Turner HA. Gender and social support - taking the bad with the good. Sex Roles. 1994; 30:521-541.

Tyndall MW, Currie S, Spittal P, Li K, Wood E, O'Shaughnessy MV, Schechter MT. Intensive injection cocaine use as the primary risk factor in the Vancouver HIV-1 epidemic. AIDS. 2003; 17:887-893. [PubMed: 12660536]

Umberson D, Crosnoe R, Reczek C. Social relationships and health behavior across the life course. Annu Rev Sociol. 2010; 36:139-159. [PubMed: 21921974]

Vingoe L, Welch S, Farrell M, Strang J. Unintentional overdose among a treatment sample of injecting drug misusers: accident or suicidal behavior? J Subst Use. 1999; 4:88-91.

Weiss RD, Griffin ML, Mirin SM. Drug abuse as self-medication for depression: an empirical study. Am J Drug Alcohol Abuse. 1992; 18:121-129. [PubMed: 1562010]

Wood E, Hogg RS, Bonner S, Kerr T, Li K, Palepu A, Guillemi S, Schechter MT, Montaner JS. Staging for antiretroviral therapy among HIV-infected drug users. JAMA. 2004; 292:1175-1177. [PubMed: 15353528]

Wood E, Hogg RS, Lima VD, Kerr T, Yip B, Marshall BD, Montaner JS. Highly active antiretroviral therapy and survival in HIV-infected injection drug users. JAMA. 2008; 300:550-554. [PubMed: 18677027]

Wood E, Stoltz JA, Montaner JS, Kerr T. Evaluating methamphetamine use and risks of injection initiation among street youth: the ARYS study. Harm Reduct J. 2006a; 3:18. [PubMed: 16723029] 
Wood E, Stoltz JA, Montaner JS, Kerr T. Evaluating methamphetamine use and risks of injection initiation among street youth: the ARYS study. Harm Reduct J. 2006b; 3:18. [PubMed: 16723029] 


\section{Table 1}

Baseline characteristics of IDU participating in At Risk Youth Study (ARYS), Vancouver Injection Drug Users Study (VIDUS II) and AIDS Care Cohort to Evaluate Access to Survival Services (ACCESS) cohorts in Vancouver, British Columbia $(\mathrm{n}=1,931)$.

\begin{tabular}{lrr}
\hline \multicolumn{1}{l}{$\mathbf{n}$} & $\mathbf{\%}$ \\
\hline \multicolumn{1}{l}{ Sex } & & \\
Female & 653 & 33.8 \\
$\quad$ Male & 1,278 & 66.2 \\
Age & & \\
$\quad$ <20 years & 69 & 3.6 \\
> 20 years & 1,862 & 96.4 \\
Finished High School & & \\
No & 1,044 & 54.1 \\
Yes & 887 & 45.9 \\
Birthplace & & \\
Canada & 1,231 & 63.8 \\
Foreign-Born & 700 & 36.3 \\
Depressive Symptoms & & \\
No & 743 & 41.7 \\
Yes & 1,040 & 58.3 \\
Sexual Orientation & & \\
Homosexual & 281 & 14.6 \\
Heterosexual & 1,650 & 85.5 \\
Social Support & & \\
None & 406 & 21.0 \\
1-2 & 1,317 & 68.2 \\
3 or more & 208 & 10.8
\end{tabular}

Homeless

$\begin{array}{crr}\text { No } & 1,148 & 59.5 \\ \text { Yes } & 783 & 40.6 \\ \text { Relationship status } & & \\ \text { No } & 1,361 & 70.5 \\ \text { Yes } & 570 & 29.5\end{array}$

$\begin{array}{crr}\text { Welfare } & & \\ \text { No } & 264 & 13.7 \\ \text { Yes } & 1,667 & 86.3\end{array}$

Jail in the last 6 months

$\begin{array}{lrr}\text { No } & 1,588 & 82.2 \\ \text { Yes } & 343 & 17.8\end{array}$

Binge alcohol in the last 6 months

$\begin{array}{lrr}\text { No } & 1,419 & 73.5 \\ \text { Yes } & 512 & 26.5\end{array}$

Heroin use in the last 6 months 


\begin{tabular}{lrr}
\hline & n & \% \\
\hline No & 878 & 45.5 \\
Yes & 1,053 & 54.5
\end{tabular}

Cocaine use in the last 6 months

$\begin{array}{lrr}\text { No } & 1,122 & 58.1 \\ \text { Yes } & 809 & 41.9\end{array}$

Crystal Meth use in the last 6 months

$\begin{array}{lrr}\text { No } & 1,531 & 79.3 \\ \text { Yes } & 400 & 20.7\end{array}$

Morphine use in the last 6 months

$\begin{array}{lrr}\text { No } & 1,564 & 81.0 \\ \text { Yes } & 367 & 19.0 \\ \text { Speed use in the last } 6 & \text { months } & \\ \text { No } & 1,633 & 84.6 \\ \text { Yes } & 298 & 15.4\end{array}$

HIV Status

$\begin{array}{lrr}\text { Negative } & 1,321 & 69.1 \\ \text { Positive } & 592 & 31.0\end{array}$

Help with injecting

\begin{tabular}{lrr} 
No & 1487 & 77.0 \\
Yes & 444 & 23.0 \\
Methadone Treatment & & \\
No & 1,122 & 58.1 \\
Yes & 809 & 41.9 \\
Cohort & & \\
ARYS & 326 & 16.9 \\
ACCESS & 578 & 29.9 \\
VIDUS & 1,027 & 53.2 \\
\hline
\end{tabular}

Drug Alcohol Depend. Author manuscript; available in PMC 2014 October 01. 


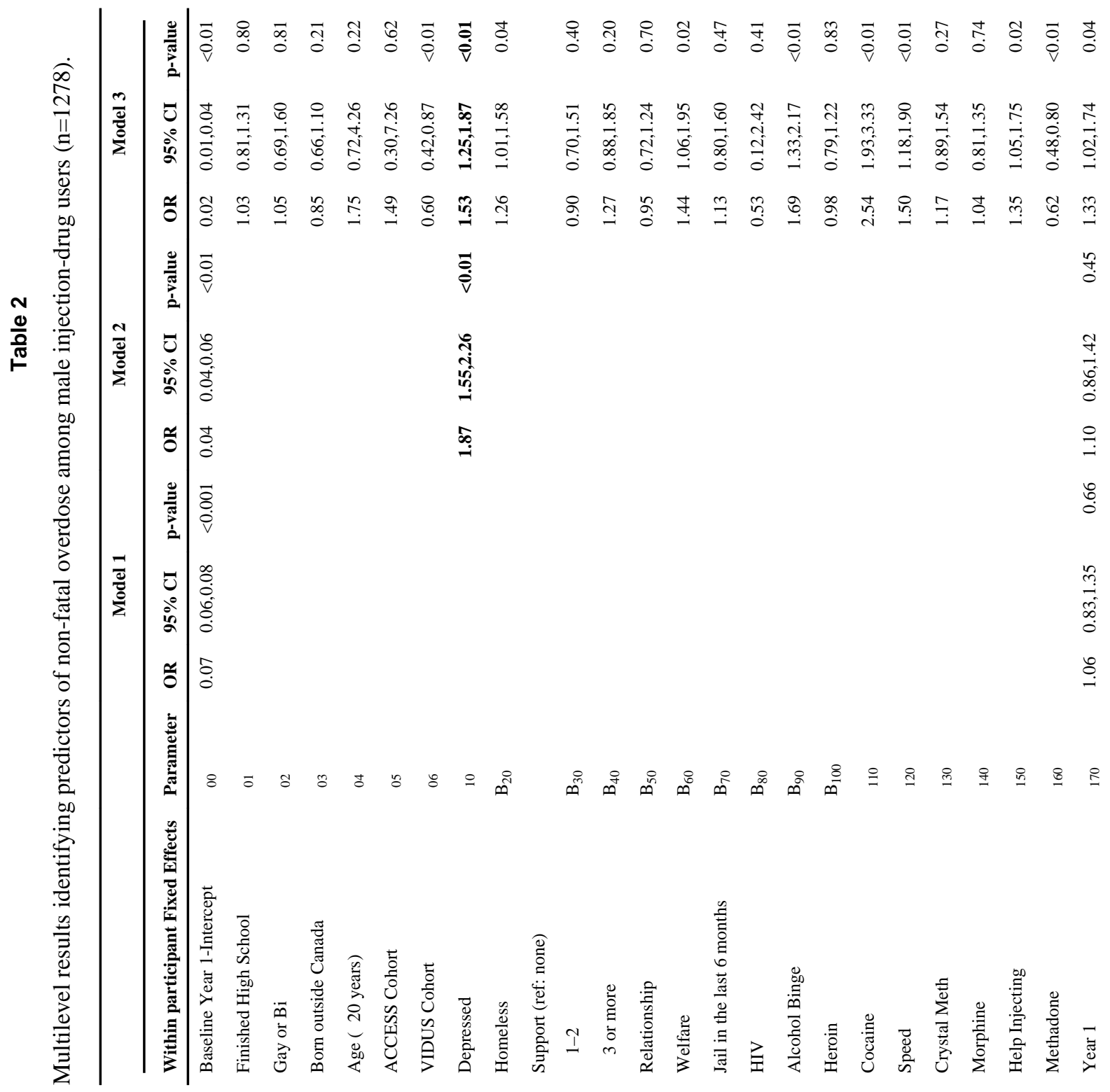




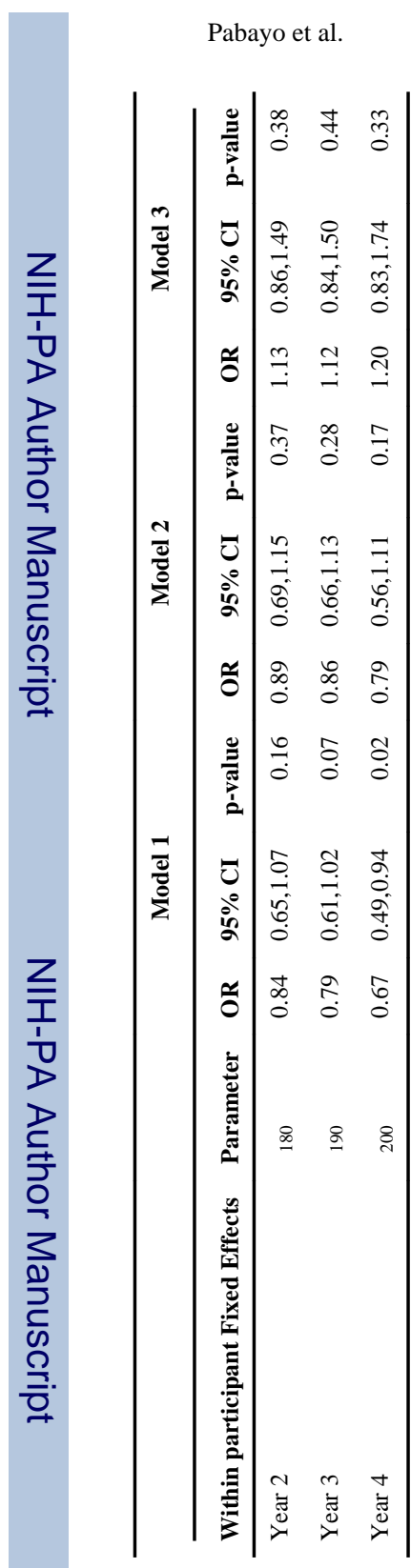

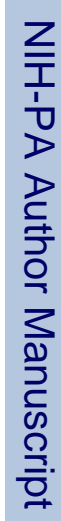




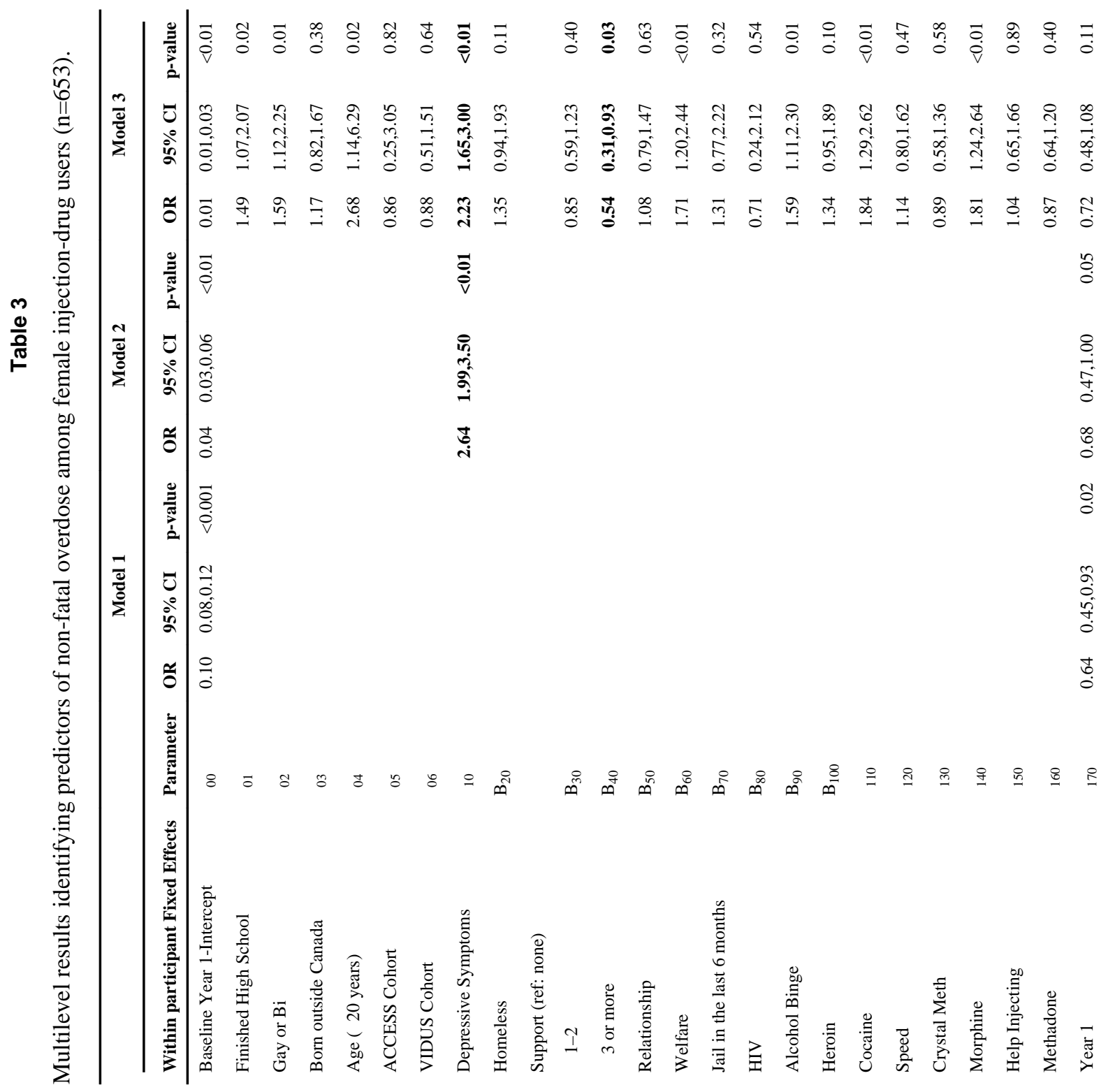




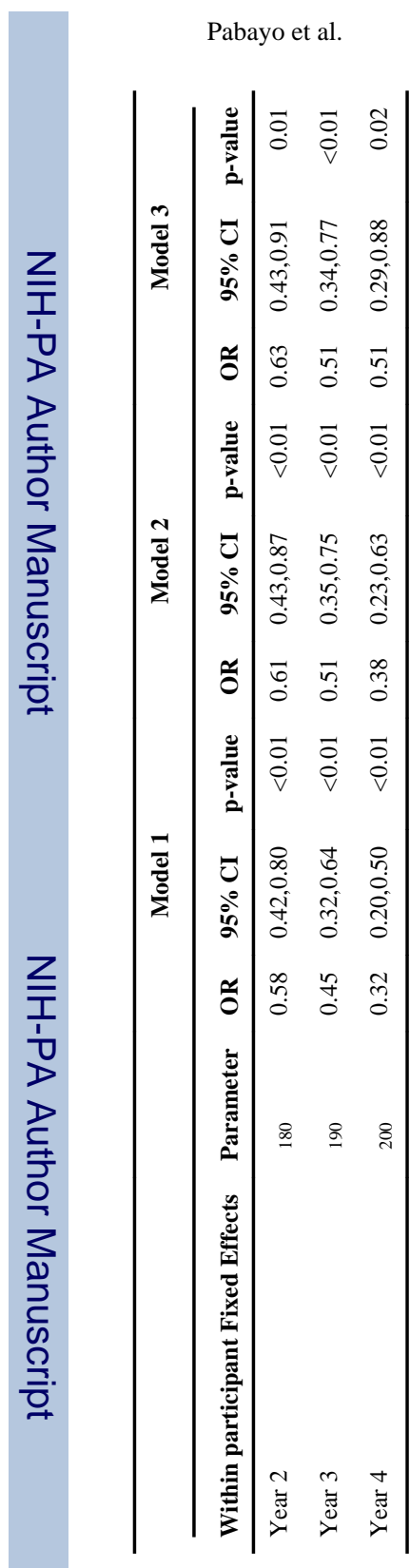

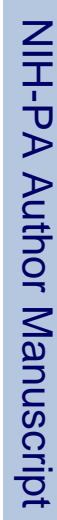

